九州大学学術情報リポジトリ

Kyushu University Institutional Repository

$\mathrm{Si}$ and $\mathrm{Cr}$ Doping Effects on Growth and Mechanical Properties of

ULtrananocrystallineDiamond/Amorphous Carbon Composite Films Deposited on Cemented Carbide Substrates by Coaxial Arc Plasma Deposition

Egiza, Mohamed

Mechanical Engineering Department, Kafrelsheikh University | Department of Applied Science for Electronics and Materials, Kyushu University

Naragino, Hiroshi

Department of Applied Science for Electronics and Materials, Kyushu University

Tominaga, Aki

Department of Applied Science for Electronics and Materials, Kyushu University

Murasawa, Kouk i

OSG Corporation

他

https://doi.org/10.5109/1657738

出版情報: Evergreen. 3 (1)，pp.32-36，2016-03. Green Asia Education Center バージョン：

権利関係 : 


\title{
Si and Cr Doping Effects on Growth and Mechanical Properties of Ultrananocrystalline Diamond/Amor- phous Carbon Composite Films Deposited on Cemented Carbide Substrates by Coaxial Arc Plasma Deposition
}

\author{
Mohamed Egiza, 2,*, Hiroshi Naragino², Aki Tominaga², Kouki Murasawa ${ }^{3}$, \\ Hidenobu Gonda ${ }^{3}$, Masatoshi Sakurai ${ }^{3}$, Tsuyoshi Yoshitake ${ }^{2, * *}$ \\ ${ }^{1}$ Mechanical Engineering Department, Kafrelsheikh University, Kafrelsheikh, 33516, Egypt \\ 2 Dept. of Appl. Sci. for Electr. and Mat., Kyushu University, Kasuga, Fukuoka 816-8580, Japan \\ ${ }^{3}$ OSG Corp. 2-17 Shirakumo-cho, Toyokawa, Aichi 442-0018, Japan
}

Author to whom correspondence should be addressed, *E-mail: mohamed_egiza@kyudai.jp,**E-mail: tsuyoshi_yoshitake@kyudai.jp

(Received January 22, 2016; accepted February 24, 2016).

\begin{abstract}
Si and $\mathrm{Cr}$ doped ultrananocrystalline diamond/amorphous carbon composite films were deposited on cemented carbide (WC-Co) substrates by using coaxial arc plasma deposition with Si and $\mathrm{Cr}$ blended graphite targets. The undoped films deposited at room temperature and a repetition rate of arc discharges of $1 \mathrm{~Hz}$ have the maximum hardness of $51 \mathrm{GPa}$ and Young's modulus of 520 GPa. With increasing substrate temperature and repetition rate, the hardness and modulus are degraded, which might be because the growth of $\mathrm{sp}^{2}$ bonds is thermally enhanced. The doping of $\mathrm{Cr}$ and $\mathrm{Si}$ degrades the hardness and modulus. From energy-dispersive X-ray spectroscopic measurements, the diffusion of Co atoms from the substrates into the films were observed for the Sidoped films. Since the Co diffusion induce the graphitization due to the catalytic effects, the degraded hardness and modulus of the Si doped films should be attributable to the catalytic effects of Co. For the Cr-doped films, the degraded hardness and modulus might be because of the Co catalytic effects being enhanced by the bombardment of $\mathrm{Cr}$ atoms whose atomic weight is much larger than that of $\mathrm{C}$ and the formation of chromium carbide. It was found that the doping of Si and Cr for the deposition of UNCD/a-C films deposited on WC-Co by CAPD is not effective for the improvement of the hardness and modulus
\end{abstract}

Keywords: Nanodiamond, Hard coating, Coaxial arc plasma deposition, CAPD, Nanoindentation, Si doping, Cr doping

\section{Introduction}

Nanodiamond is a new candidate as carbon-based hard coating materials for machining nonferrous metals and alloys, owing to the superior properties such as good thermal stability, low friction, and high wear resistance. Ultrananocrystalline diamond (UNCD)/amorphous carbon (a-C) composite (UNCD/a-C) films are composed of a large number of diamond grains with diameters of less than $10 \mathrm{~nm}$ and an a-C matrix. The thermal stability and film surface smoothness are superior to those of hard a-C, so-called diamond like-carbon (DLC) ${ }^{1,2)}$, and polycrystalline diamond (PCD), respectively. The achievement of high hardness and modulus are important keys for the application of UNCD/a-C to hard coatings ${ }^{3)}$.

Nanodiamond films have been prepared mainly by chemical vapour deposition (CVD) thus far. On the other hand, there have been few studies employing physical vapour deposition (PVD). Cathodic arc discharge, which is a kind of PVD, has ever been employed for the deposition of $\mathrm{sp}^{3}$-rich a-C films ${ }^{4}$, since highly energetic carbon ions, which are desirable for the formation of $\mathrm{sp}^{3}$ bonds, are provided onto substrates ${ }^{5,6,7)}$. In addition to the specifics of cathodic arc discharge, coaxial arc plasma deposition (CAPD) has the following distinctive feature: a coaxial arc plasma gun is equipped with an anodic cylinder that can bunch ions ejected from a cathodic graphite rod located inside the cylinder. Owing to this structure, a supersaturated condition with highly energetic ions can be realized, which is desired for the growth of UNCD crystallites ${ }^{8)}$.

Cemented carbide (WC-Co) comprising WC and a Co binder is a typical cutting tool material ${ }^{9)}$. Since Co in WCCo acts as a catalyst that facilitates graphitization ${ }^{10,11)}$, 
polycrystalline diamond coating by CVD is made after the preferential etching of Co chemically prior to the coating $^{12)}$. The catalytic effects are enhanced with increasing substrate temperature. Therefore, deposition at low temperatures is preferable.

Doping foreign elements such as $\mathrm{Si}$ and $\mathrm{Cr}$ have been applied to hard a-C films for improving mechanical properties, stabilizing the chemical bonding structures of the films, and relaxing internal stresses in the films. However, the results of doping effects on the hardness are in disagreement among research groups. For example, it was reported that $\mathrm{Cr}$ incorporation into carbon films enhances the hardness by $10 \%{ }^{13)}$ and $30 \%^{14)}$, whereas there are reports that show opposite results ${ }^{15}$. For Si doping, it has been considered that $\mathrm{Si}$ atoms suppress the formation of $\mathrm{sp}^{2}$ bonds and facilitate the formation of $\mathrm{sp}^{3}$ bonds ${ }^{16)}$. On the other hand, a contradictory result was reported ${ }^{17)}$. There have been few reports on the doping effects of $\mathrm{Cr}$ and Si on UNCD/a-C films thus far.

Previously, our group have reported the deposition of UNCD/a-C films on Si substrates at elevated substrate temperatures in a base pressure atmosphere by CAPD without the pretreatment of substrates with diamond powder ${ }^{18)}$. In this study, the deposition of UNCD/a-C films by CAPD was applied to WC-Co substrates as hard coatings, and the doping effects of Si and Cr on the film growth and mechanical properties were investigated.

\section{Experimental Procedures}

UNCD/a-C films were deposited on WC-Co substrates with dimensions of $10 \mathrm{~mm}$ diameter and $4 \mathrm{~mm}$ thickness by CAPD with graphite targets. The inside of the vacuum apparatus was evacuated to base pressures of less than $10^{-4} \mathrm{~Pa}$ by a turbo molecular pump. An arc plasma gun equipped with a $720 \mu \mathrm{F}$ capacitor was operated at a applied voltage of $100 \mathrm{~V}$. The film deposition was carried out at different substrate temperatures and repetition rates of arc discharge as shown in Table 1.

The crystalline structures were examined by powder Xray diffraction (XRD) using $12 \mathrm{keV} \mathrm{X}$-rays from synchrotron radiation at beamline 15 of Kyushu Synchrotron

Table 1: Comparison in mechanical properties among films deposited at different substrate temperature and repetition rate of arc discharge.

\begin{tabular}{|c|c|c|c|}
\hline & Sample 1 & Sample 2 & Sample 3 \\
\hline Target & $\begin{array}{c}\text { undoped } \\
\text { graphite }\end{array}$ & $\begin{array}{c}\text { undoped } \\
\text { graphite }\end{array}$ & $\begin{array}{c}\text { undoped } \\
\text { graphite }\end{array}$ \\
\hline Sub. Temp. $\left[{ }^{\circ} \mathrm{C}\right]$ & 550 & RT & RT \\
\hline Rep. Rate $[\mathrm{Hz}]$ & 5 & 5 & 1 \\
\hline Thickness $[\mu \mathrm{m}]$ & $4-6$ & $2-3$ & $2-3$ \\
\hline Hardness $[\mathrm{GPa}]$ & $\mathbf{1 7 . 3}$ & $\mathbf{3 1 . 8}$ & $\mathbf{5 1 . 3}$ \\
\hline Modulus $[\mathbf{G P a}]$ & $\mathbf{1 6 9}$ & $\mathbf{2 9 4}$ & $\mathbf{5 2 0}$ \\
\hline
\end{tabular}

Light Research Center/Saga Light Source. For its measurement, the film was peeled off from the substrate and powdered. The powder was filled in a borosilicate glass capillary with an inside diameter of $0.3 \mathrm{~mm}$. The top-view and cross-sectional images were taken by scanning electron microscopy (SEM). The chemical compositions of the films were estimated from the energy-dispersive X-ray spectroscopic (EDX) measurements. The hardness and modulus were measured by nanoindentation ${ }^{19)}$. The applied indentation load was $0.5 \mathrm{mN}$. Load-displacement curves of indentation were measured at ten points for each sample to confirm the reproducibility.

\section{Results and Discussion}

To confirm the existence of diamond grains in the films, XRD measurements with synchrotron radiation were examined. Figure 1 shows the typical XRD pattern transformed from Debye-Scherrer rings recorded on an imaging plate. Diffraction peaks due to diamond-111 and 220 are observed. They are extremely broad, which indicates that the size of UNCD grains is extremely small. The grain size was estimated to be approximately $2.4 \mathrm{~nm}$ using the Scherrer equation ${ }^{20)}$. There are no peaks due to graphite, which implies that graphite used as the carbon source is almost completely decomposed into atomic species by arc discharge. The graphitization of UNCD grains is negligible on the non-seeded WC-Co substrate since the UNCD

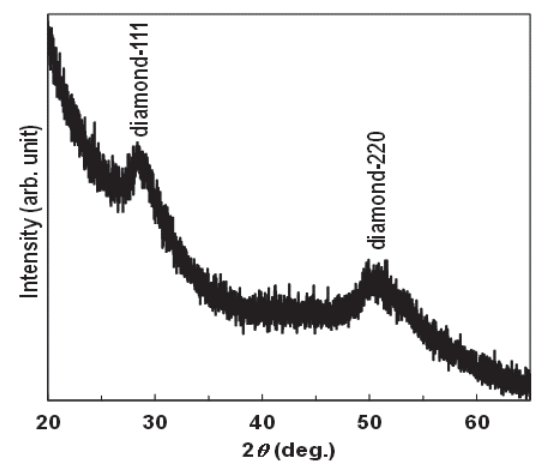

Fig. 1. XRD pattern of undoped UNCD/a-C film deposited at room temperature.
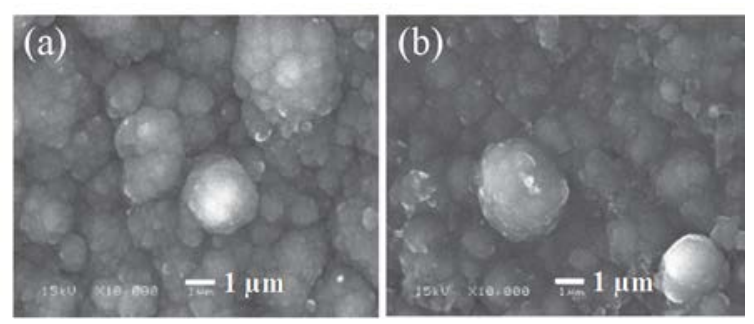

Fig. 2. SEM images of surface of (a) sample 1 and (b) sample 2 . 


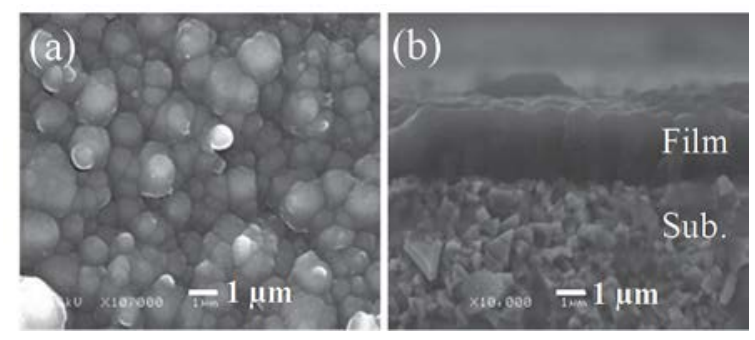

Fig. 3. (a) Top-view and (b) cross-sectional SEM images of undoped UNCD/a-C film.
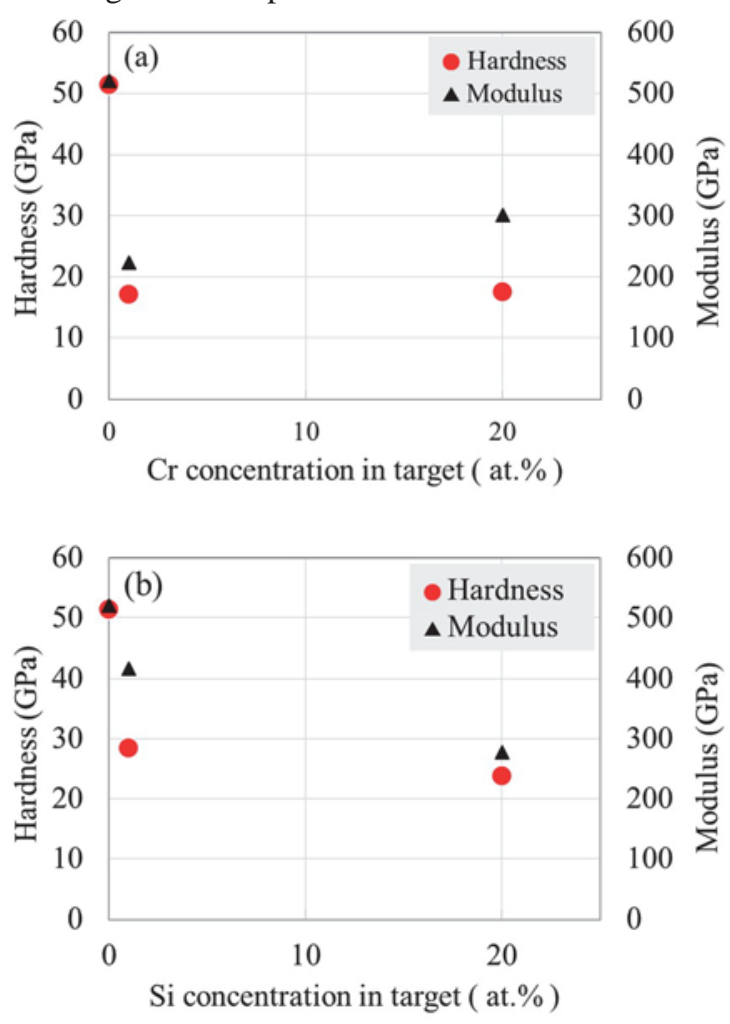

Fig.4. Change in hardness and Young's modulus for (a) $\mathrm{Cr}$ and (b) Si contents.

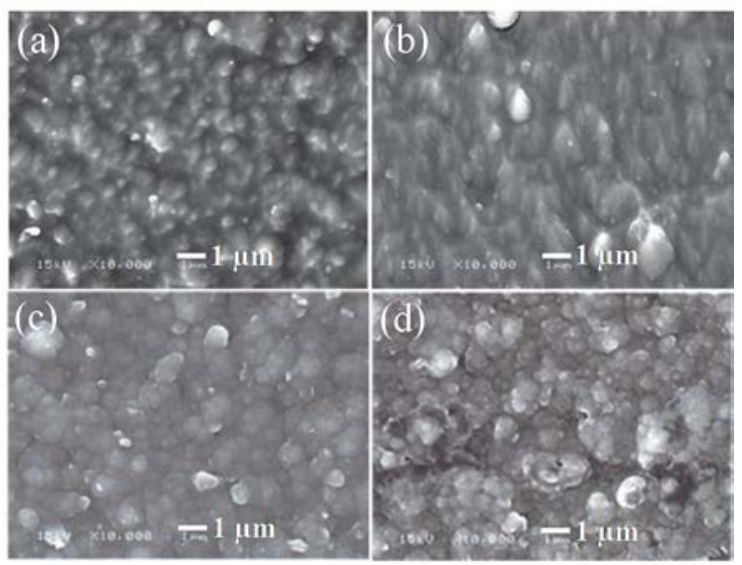

Fig. 5. Top-view SEM images of (a) 1 at.\% Cr, (b) 20 at.\% Cr, (c) 1 at.\% Si and (d) 20 at.\% Si doped UNCD/a-C films. grain size is comparable to that of UNCD/a-C films deposited on Si substrates.

Whereas films deposited on $\mathrm{Si}$ at a substrate temperature of $550{ }^{\circ} \mathrm{C}$ exhibit a hardness of approximately $23 \mathrm{GPa}^{21)}$, a film (Sample 1) deposited on WC-Co substrate exhibit a hardness of $17.3 \mathrm{GPa}$, as shown in Table 1. The hardness is slightly degraded by employing WC-Co substrates. This is probably mainly attributable to the catalytic effects of Co in the WC-Co substrate.

A film (Sample 2) deposited at room temperature exhibits a hardness of $31.8 \mathrm{GPa}$ and Young's modulus of $294 \mathrm{GPa}$. The hardness and modulus are remarkably enhanced with decreasing substrate temperature. This indicates that the Co catalytic effects are suppressed by the low substrate-temperature deposition. As shown in Fig. 2, Sample 2 exhibits the larger size of particles comprising the films as compared with that of Sample 1. Although the formation process of the micron-sized particles is unknown, the size might be enlarged by the Co catalytic effects somehow.

A film (sample 3) deposited at a repetition rate of $1 \mathrm{~Hz}$ shows $51.3 \mathrm{GPa}$ hardness and $520 \mathrm{GPa}$ modulus. These values are extremely large and comparable to the maximum values of hydrogen-free $\mathrm{DLC}^{22,23,24,25,26)}$. The hardness and modulus are evidently enhanced with decreasing repetition rate from 5 to $1 \mathrm{~Hz}$. This might be explained thermally also. The interval time between arc discharges increases from $200 \mathrm{~ms}$ to $1 \mathrm{~s}$ for the decrease in the repetition rate. The lengthened interval time seems to be effective on temporally cooling the film surface, which might result in the suppression of the Co catalytic effects. As shown in Fig. 3, the particle size of Sample 3 is evidently small as compared with those of Sample 1 and 2. The growth of particles are suppressed by the decrease of the repetition rate.

For the film prepared at room temperature and $1 \mathrm{~Hz}$, doping effects of $\mathrm{Si}$ and $\mathrm{Cr}$ were investigated. Si and $\mathrm{Cr}$ doped UNCD/a-C films were deposited with $\mathrm{Si}$ and $\mathrm{Cr}$ doped graphite targets. The dopant contents in the target were 1 and 20 at.\%.

As shown in Fig. 4, the hardness and modulus decrease with increasing $\mathrm{Si}$ and $\mathrm{Cr}$ contents. The hardness and modulus of the Cr-doped films are lower than those of the Si-doped films. As a reason for it, since the mass of $\mathrm{Cr}$ is much larger than that of $\mathrm{Si}$, it is expected that the bombardment of negatively charged $\mathrm{Cr}$ ions on the substrate surface highly activates the catalytic effects of Co in the WC-Co substrate. As shown in Fig. 5, the Cr-doped films exhibited rough surfaces as compared with those of the Si-doped films. As another reason, the formation of chromium carbide might soften the films. Actually, Crdoped UNCD/a-C films prepared on different substrates at similar preparation conditions exhibited diffraction peaks due to the formation of chromium carbide.

Figure 6 shows the EDX spectra of the undoped and Sidoped films. Whereas the undoped film shows no peak due to $\mathrm{Co}$ in the spectrum, both Si-doped films evidently exhibit Co peaks. This indicates that the diffusion of Co 

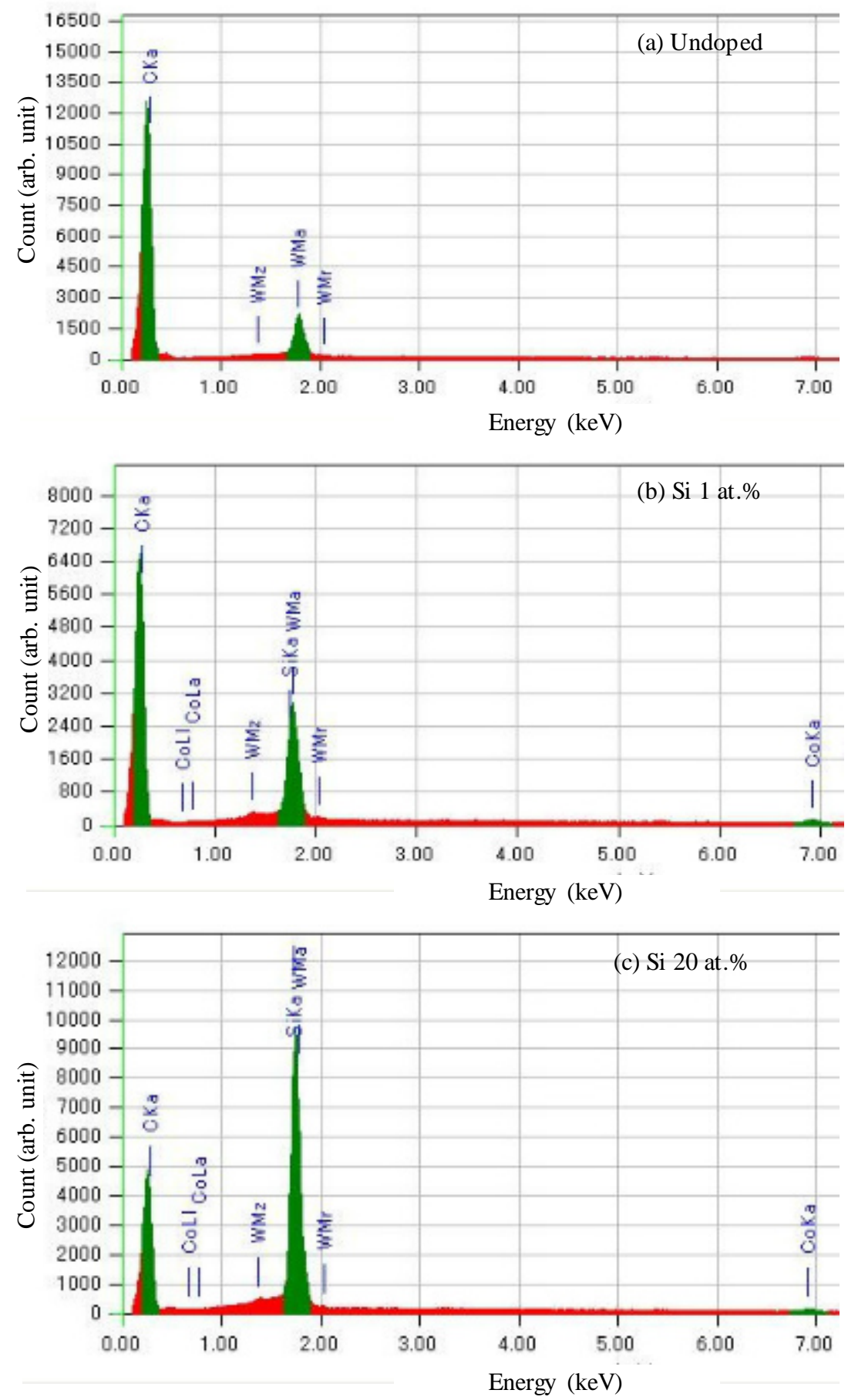

Fig. 6. EDX spectra of (a) undoped, (b) 1 at.\% Si-doped, and (c) 20 at.\% Si-doped films.

atoms from the substrate into the films during the deposition is enhanced in the Si-doped films. Although it is known that the incorporation of Si atoms facilitates the formation of $\mathrm{sp}^{3}$ bonds ${ }^{27)}$, the hardness and modulus are evidently decreased by the Si doping. This should be due to the catalytic effects of Co atoms that diffused into the films. The bonding length of $\mathrm{C}-\mathrm{Si}$ is $1.89 \AA$, which is longer than that (1.54 $\AA$ ) of $C-C^{27)}$, which might allow the diffusion of Co atoms into the films.

\section{Conclusion}

UNCD/a-C films were deposited on WC-Co substrates by CAPD, and the films were structurally and mechanically evaluated. The growth of UNCD/a-C films by CAPD without the pretreatment of WC-Co substrates with diamond powder was experimentally demonstrated. The deposition of the films at low temperatures is effective for suppressing graphitization due to the catalytic effects of Co atoms in WC-Co. For the Cr doping, the hardness and modulus were degraded, which might be because of the 
Co catalytic effects being enhanced by the bombardment of $\mathrm{Cr}$ atoms whose atomic weight is much larger than that of $\mathrm{C}$ and the formation of chromium carbide. The doping of $\mathrm{Si}$ atoms enhances the diffusion of Co atoms from the substrates into the films, which results in degrading the hardness and modulus as compared with those of the undoped films.

\section{Acknowledgments}

This work was partially supported by Osawa Scientific Studies and Grants Foundation. The X-ray diffraction measurements using synchrotron radiation were performed at BL 15 of Kyushu Synchrotron Light Research Center/Saga Light Source (Proposal Nos. 1505044S and 1510095S).

\section{References}

1) C. Jongwannasiri, X. Li, and S. Watanabe, Mat. Sci. \& Applic., 4, 630 (2013).

2) D.R. Tallant, J.E. Parmeter, M.P. Siegal, and R.L. Simpson, Dia. \& Rel. Mat., 4, 191 (1995).

3) A. Inspektor, C.E. Bauer, and E.J. Oles, Surf. \& Coat. Tech., 68, 359 (1994).

4) M. Chhowalla, C. A. Davis, M. Weiler, B. Kleinsorge, and G. A. J. Amaratunga, J. Appl. Phys., 79, 2237 (1996).

5) D.Liu, G. Benstetter, E. Lodermeier, J. Zhang, Y. Liu, and J. Vancea, J. Appl. Phys., 95, 7624 (2004).

6) J.J.Cuomo, D. L. Pappas, J. Bruley, J. P. Doyle, and K. L. Saenger, J. Appl. Phys., 70, 1706 (1991).

7) M.Chhowalla, J. Robertson, C. W. Chen, S. R. P. Silva, C. A. Davis, G. A. J. Amaratunga, and W. I. Milne, J. Appl. Phys., 81, 139 (1997).

8) K. Hanada, T. Yoshitake, T. Nishiyama, and K. Nagayama, Jpn. J. Appl. Phys., 49, 08JF09 (2010).

9) S. Kubelka, R. Haubner, B. Lux, R. Steiner, G. Stingeder, M. Grasserbauer, Dia. \& Rel. Mat., 3, 1360 (1994).

10) M. Lessiak, R. Haubner., Surf. \& Coat. Tech., 230, 119 (2013).

11) B. S. Park, Y.-J. Baik, K.-R. Lee, K. Y. Eun, and D. H. Kim, Dia. \& Rel. Mat., 2, 910 (1993).

12) A. Lindlbauer, R. Haubner, and B. Lux, Wear, 159, 67 (1992).

13) S.K. Pal, J. Jiang, and E.I. Meletis, Surf. \& Coat. Tech., 201(18), 7917 (2007).

14) W. Dai, P. Ke, and A. Wang, Vacuum. 85(8), 792 (2011).

15) V. Singh, J.C. Jiang, and E.I. Meletis, Thin Solid Films, 489 (1-2), 150 (2005).

16) X. M. He, K. C. Walter, M. Nastasi, S.-T. Lee, and M. K. Fung, J. Vac. Sci. Tech. A, 18, 2143 (2000).

17) M. Ikeyama, S. Nakao, Y. Miyagawa, and S. Miyagawa, Surf. \& Coat. Tech., 191, 38 (2005).
18) K. Hanada, T. Yoshida, Y. Nakagawa, and T. Yoshitake, Jpn. J. Appl. Phys., 49, 125503 (2010).

19) S. Miyake, T. Hashizume, W. Kurosaka, M. Sakurai, and M. Wang, Surf. \& Coat. Tech., 202, 1023 (2007).

20) A.L. Patterson, Phy. Rev., 56, 978 (1939).

21) T. Yoshitake, Y. Nakagawa, A. Nagano, R. Ohtani, H. Setoyama, E. Kobayashi, K. Sumitani, Y. Agawa, and K. Nagayama, Jpn. J. Appl. Phys., 49, 015503 (2010).

22) H. J. Scheibe and B. Schultrich, Thin Solid Films, 246, 92 (1994).

23) W. Zhang, A. Tanaka, K. Wazumi, and Y. Koga, Dia. \& Rel. Mat., 11, 1837 (2002).

24) Y. Wang, H. Li, L. Ji, F. Zhao, X. Liu, Q. Kong, Y. Wang, W. Quan, and H. Zhou, J. Phys., 43, 505401 (2010).

25) P. Kodali, K. C. Walter, and M. Nastasi, Tribology Int., 30, 591 (1997).

26) D. Sheeja, B. K. Tay, and L. N. Nung, Wear, 249, 433 (2001).

27) S. Ong, S. Zhang, H. Du, and D. Sun, Dia. \& Rel. Mat., 16, 1628 (2007) 